of the glomerular filtration rate at short intervals of time, thus providing information which previous techniques had failed to do. But the method unfortunately cannot be carried out except in special centres with accurate isotope equipment. In addition, the mathematics are complicated, and to obtain quick results a computer had to be used to solve the simultaneous equations necessitated by use of the two isotopes.

Another way of using labelled vitamin $B_{12}$ to determine the glomerular filtration rate has been pioneered by $M$. Slapak and D. M. Hume. ${ }^{4}$ Their method ran into criticism, ${ }^{5-7}$ but it has promise and is worth further study.

In summary, while all specialists in renal disease want a precise and simple method for determination of the glomerular filtration rate, a completely satisfactory and acceptable technique has still not been discovered. Probably the best available method is that of Breckenridge and Metcalfe-Gibson ${ }^{2}$ suitably refined by simultaneous estimation of the degree of protein binding of labelled vitamin $B_{12}$ during the mid-point of the clearance period.

\section{The Umbilical Cord}

As the embryonic disc becomes flexed and folded in the earliest stages of development the primitive umbilical ring appears on the ventral aspect of the embryo. Through this ring pass the connecting stalk with the allantois and umbilical vessels, the yolk-sac stalk and vitelline vessels, and the extraembryonic coelomic cavity, which temporarily contains some of the intestinal loops, which herniate therein. By the fifth week of foetal life, the umbilical ring constricts so that its contents become crowded together, thus forming the primitive umbilical cord. Shortly afterwards the intestinal loops withdraw from the cord into the abdominal cavity, and the coelom contained within the cord is obliterated. Then the allantois, vitelline duct, and its vessels disappear, and all that persist are the umbilical vessels surrounded by Wharton's jelly. At first the cord is about the thickness of the index finger, and about $2 \mathrm{ft}$. $(60 \mathrm{~cm}$.) in length. Its striking feature is its screw-like arrangement.

Details of the distinctive structure of the cord are of considerable interest bccause they have an important bearing on the dynamics of the placental circulation. Moreover, because the umbilical vessels develop in isolation and in a fluid environment, their structure may give information on how blood vessels grow. It is interesting that vascular anomalies of the cord such as arteriovenous fistulae have often been described. ${ }^{1}$

P. Malpas and E. M. Symonds ${ }^{2}$ have recently studied the causes and effects of the helical, or screwlike, arrangement of the umbilical arteries and vein. Cords were obtained at caesarian section or at abdominal hysterotomy for therapeutic abortion so that their undistorted structure could be studied. The fully developed helical structure was present in the youngest foetus examined-aged eight weeks. The number of twists were not clearly related to the length of the cord, varying from four in a cord of 20 in. $(50 \mathrm{~cm}$.) to 29 in a cord of $30 \mathrm{in}$. $(75 \mathrm{~cm}$.). These findings showed that the helical structure of the cord is established at a very early stage in development of the foetus and that the cord gains in length not by an increase in the number of twists but by a progressive increase in the length of the pitch of the

Wentworth, P., f. Anat. (Lond.), 1965, 99, 273.

'Malpas, P., and Symonds, E. M., Surg. Gynec. Obstet., 1966, 123, 746. primary helix. It is of interest that nearly three-quarters of the cords examined had a left-handed twist, $19 \%$ had twists to the right, and $8 \%$ were anomalous, some being straight in all or part of their length, others showing a change in direction of the helix at some point along the cord, and yet others having a U-turn in one or both arteries.

The vessels of the cord, like all hollow tubes subject to twist, are susceptible to snarling. It seems likely that the screwlike arrangement of the cord minimizes the risk of obstructive snarls, especially in early pregnancy when the foetus is freely mobile. Indeed, Malpas and Symonds describe observing a 10-week foetus, obtained by abdominal hysterotomy, within its intact amniotic sac. Moving the specimen to allow the foetus to fall forward was seen to shorten the cord and the pitch of its helix. At a certain point of shortening an obstructive snarl appeared but was straightened out immediately by the pressure of blood within the vessels, since the foetal heart was still beating at this stage. There may be a relationship between unresolved snarls and spontaneous abortion. Indeed, in many such specimens the cord is seen to be contracted into a tightly wound and irregular coil. These authors also suggest that the irregular helical pattern seen in some cords at term may indicate that the vessels are reaching their functional limit.

\section{Uveoparotitis}

Over fifty years ago G. Schumacher ${ }^{1}$ and F. Bering and his colleagues $^{2}$ independently drew attention to a form of iritis associated with disease of the skin or of the parotid or submaxilliary salivary glands. Since all these patients showed positive tuberculin reactions, it was concluded that they had tuberculous iritis. At the same time the Danish ophthalmologist C. F. Heerfordt ${ }^{3}$ described the condition of "febris uveoparotidea subchronica," which was characterized by uveitis and enlargement of the parotid glands, ran a chronic and usually febrile course, and was frequently complicated by cranial nerve palsies (especially of the seventh nerve) with pleocytosis of the cerebrospinal fluid. Heerfordt described three cases and referred to other published examples, though, since some of these latter cases had been ascribed to mumps, he also concluded that the aetiology in his three cases was the same.

During the next twenty-five years the aetiological role of mumps or tuberculosis ${ }^{4}$ in Heerfordt's syndrome was fiercely debated. The controversy ended in 1937, however, when authors $^{5-8}$ independently in Scandinavia, Holland, France, and the United States recognized the fact that uveoparotid fever was merely another manifestation of sarcoidosis. Thus J. Waldenström's ${ }^{5}$ cogent reasons against a tuberculous aetiology were the negative tuberculin skin tests, the absence of caseation in the tissues, and the inability to isolate tubercle bacilli from the lesions; while in favour of sarcoidosis were the similarity of the skin lesions, both to the naked eye and histologically, and the presence of hyperglobulinaemia in both uveoparotitis and sarcoidosis.

Schumacher, G., Münch. med. Wschr., 1909, 56, 2664.

Bering, F., Derm. Z., 1910, 17, 404.

Heerfordt, C. F., Albrecht v. Graefes Arch. Ophthal., 1909, 70, 254.

Garland, H. G., and Thompson, J. G., Quart. f. Med., 1933, 26, 157.

Waldenström, J., Acta med. scand., 1937, 91, 53.

Bruins Slot, W. J., Ned. T. Geneesk., 1936, 80, 2859.

Pautrier, L. M., Bull. Soc. méd. Hôp. Paris, 1937, 53, 1608.

Longcope, W. T., and Pierson, J. W., Bull. Fohns Hopk. Hosp., 1937, $60,223$.

' Greenberg, G., Anderson, R., Sharpstone, P., and James, D. G., Brit. med. 7., 1964, 2, 861 . 